Volume 10 Issue 2

OO

RESEARCH ARTICLE
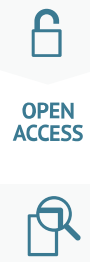

PEER REVIEWED

\title{
The geopolitics of 'platforms': the TikTok challenge
}

Joanne E. Gray Queensland University of Technology joanne.e.gray@qut.edu.au

DOI: https://doi.org/10.14763/2021.2.1557

Published: 11 May 2021

Received: 6 October 2020 Accepted: 9 April 2021

Competing Interests: The author has declared that no competing interests exist that have influenced the text.

Licence: This is an open-access article distributed under the terms of the Creative Commons Attribution 3.0 License (Germany) which permits unrestricted use, distribution, and reproduction in any medium, provided the original work is properly cited. https://creativecommons.org/licenses/by/3.0/de/deed.en

Copyright remains with the author(s).

Citation: Gray, J. E. (2021). The geopolitics of 'platforms': the TikTok challenge. Internet Policy Review, 10(2). https://doi.org/10.14763/2021.2.1557

Keywords: TikTok, Platforms, Competition, China, Geopolitics

\footnotetext{
Abstract: In the international digital platform market, a handful of US companies enjoy immense cultural, economic and political power. The short form video platform TikTok provides significant competition to these US incumbents but so far policymakers have focused on the geopolitical implications of TikTok. This paper provides a content analysis of government and company sources, issued between April and August 2020, to systematically establish the geopolitics of the TikTok controversy. It is important to identify geopolitical motivations because they can obscure other factors relevant to platform politics, such as the value of competition in a highly concentrated international platform market. The paper concludes by outlining a research agenda for enhancing competition and avoiding the solidification of conventional geopolitical power dynamics in the international digital platform market.
} 


\section{Introduction}

The short form video app TikTok is the first social media 'platform' born outside the US to significantly rival the Silicon Valley incumbents. Since its rise in the short video economy, TikTok has come under intense criticism from governments around the world, resulting in outright bans in some jurisdictions (Press Information Bureau Delhi, 2020). Lawmakers have questioned whether ByteDance, the company that owns TikTok, sufficiently protects user data against access by the Chinese state. Yet, TikTok's data practices are not dissimilar to those of its US counterparts (Fowler, 2020) and the controversy over TikTok's rise in the US cannot be explained by an analysis of the company's technology, policies or practices alone. This article provides a geopolitical analysis of the political and economic contestations over TikTok that played out at the national level between the US and China from April to August 2020.

Applying a geopolitical lens to the political rhetoric and actions relating to TikTok improves understanding of the core issues that have animated this platform controversy. For at least two decades now, the US has dominated in the international digital platform market. This dominance falls within a broader geopolitical system of US hegemony that has defined the liberal world order since the end of the Cold War. Through strategic partnerships and alliances with nations around the world the US has enjoyed great economic and political power. China's economic growth destabilises a world order that centres upon US hegemony. What the TikTok controversy shows is the extent to which this geopolitical setting is affecting the politics of platforms today. It is important to identify and isolate pertinent geopolitical motivations because they can work to obscure other factors relevant to platform politics, such as the value of competition in a highly concentrated international platform market.

In most sectors, market concentration is problematic but it is particularly so in an information economy. Digital platforms are information gatekeepers, with the capacity to influence social conditions by determining the ideas and information that are shared and amplified across vast socio-technical systems. In the international platform market, a handful of US companies enjoy immense cultural, economic and political power derived from their ownership and control over platform infrastructure and data. TikTok has provided competition to these US companies and the global success of TikTok confirms that users will adopt innovative new platforms when they are made available to them, regardless of their geographic origins. If consumers are not locked in to the incumbents, there is potential for increased competition to lead to a dilution of concentrated power in the internation- 
al platform market. But this requires overcoming conventional geopolitical agendas and eschewing both US and Chinese hegemony.

\section{Platforms and geopolitics: adventures in US hegemony}

The dominance of the digital environment by Silicon Valley technology companies presents a range of social, political and economic problems, many of which are compounded by their oligopolistic status. It is undemocratic and anticompetitive to have a small number of companies own and control the systems by which we communicate, socialise and transact (Gray, 2020). The incumbent US platforms, including Facebook, Instagram, YouTube and Twitter, are also dysfunctional in their democratic role. To varying degrees, they spread and amplify misinformation and hate speech (Donzelli et al., 2018; Matamoros-Fernández, 2017), they generate and exploit data at the expense of user privacy (Burdon, 2020; Kitchin \& Lauriault, 2014), they embed unfair and harmful biases into their algorithms and technical infrastructure (Maayan \& Elkin-Koren, 2016; Pasquale, 2015), they fail to ensure the security of user data (Mann \& Daly, 2020), and they offer limited mechanisms for transparency and accountability (Suzor et al., 2019). Two decades into the new millennium, the politics of 'platforms' (Gillespie, 2010) is a highly wrought sociopolitical affair.

Lawmakers around the world are increasingly taking action to curtail the reach and influence of the dominant US platforms. From the European Union's General Data Protection Regulation (Lynskey, 2017), to the Australian Competition and Consumer Commission's investigation of the impact of Facebook and Google on competition in media and advertising (Australian Competition \& Consumer Commission, 2017), to the 2020 US congressional hearings where the heads of Google, Apple, Amazon and Facebook were questioned over the potential use of their market power to stifle competition (Romm, 2020), these lawmakers are questioning whether the activities of the dominant US platforms are legal, legitimate or fair. Given this backdrop, the open hostility evident at the level of international politics towards TikTok, a competitor to the incumbent US platforms, might appear illogical. Properly understanding the logic that underpins the political actions and rhetoric over TikTok requires that they be placed within a geopolitical context.

To systematically establish the geopolitics of the TikTok controversy, this study involves a qualitative content analysis of US and Chinese government documents issued between April and August 2020 (a period in which the Trump administration actively pursued the regulation of TikTok), as well as relevant corporate sources. 
Using keyword searches of government websites and databases, 27 documents were collected in which statements were made about TikTok by US and Chinese state officials. US sources included documents published by whitehouse.gov, specifically, transcripts of three White House briefings statements made by the US Press Secretary, one briefing statement published by the National Security Council, transcripts of eight briefing statements by President Trump, three Executive Orders by President Trump along with three related letters to the Speaker of the House and President of the Senate, and a press statement by the US Department of State authored by Mike Pompeo. Statements made by Mike Pompeo in an interview with Fox News were also reviewed. Chinese sources included eight English language transcripts of press conferences published by the Ministry of Foreign Affairs of the People's Republic of China: three held by Spokesperson Zhao Lijian and five by Spokesperson Wang Wenbin. Together, these sources contain the political positions and responses of US and Chinese state actors during a period in which the Trump administration was actively pursuing the regulation of TikTok and, notably, they present highly consistent positions on TikTok for both states. Corporate documents included fourteen official statements released by TikTok executives and one official statement by Microsoft Inc.

In accordance with a classical geopolitical approach, these sources are used to establish an objective account of a specific geopolitical context. Classical geopolitics, unlike critical geopolitics (Toal et al., 1998), is characterised by the modernist epistemological and ontological assumption that a common geopolitical reality can be observed through 'historical example, logic, common sense, visualisation, statistical analysis and rational choice' (Kelly, 2006, p. 16). A limitation of this approach is that it requires that we accept that there is an objective geopolitical context to be established in the first place. Conducting a critical geopolitical analysis of the TikTok controversy, including an examination of how geopolitical knowledge is reproduced and reinforced in this controversy, is a topic worthy of future study and the research provided in this paper should be helpful in that pursuit. However, for the purposes of this research, which is to understand the impact of the geopolitical contest between China and the US on platform politics, a classical geopolitical approach is effective. Through a classical geopolitical analysis we can improve our understanding of how state territoriality and changes in the global distribution of economic and military power are playing out in the digital environment.

The classical model of geopolitics suggests the actions and policies of a state are influenced by that state's geographical conditions (Lee, 2018). A state will have largely stable geographical conditions (Flint, 2016)-including its location, posi- 
tion in a region, resources, topography, climate, size and shape (Kelly, 2006)-and these conditions will influence how the state approaches international affairs. Geopolitical theorists recognise that historically US foreign policy has been influenced by its geographical isolation from other economic and military powers (Kelly, 2006). Unlike many European nations, for example, the US is geographically isolated, and US leaders have sought to use this position of relative isolation as insulation from national security threats. In broad terms, the US has managed its strategic interests through 'offshore balancing' (Layne, 1997). By aligning with certain 'offshore' nations, the US takes action to influence the global distribution of power, all while sustaining a position of isolation from the threat of military incursion at home. As Kelly explains, the US has had

\begin{abstract}
a rather permanent security strategy of maintaining a favorable balance of power within the rimlands of the Eurasian continent, enabled by its marine strength and by bases in certain pivotal areas (Western Europe, Persian Gulf, and Korea/Japan). Its allies and opponents might vary from time to time; yet, North America will continue unrelentingly towards this secure rimlands position framed within its advantages of great distances and isolation from likely foes, no matter what other global and regional transformations may appear (Kelly, 2006, p. 16).
\end{abstract}

Regardless of swings in specific foreign policy approaches-from 'US First' to US as primus inter pares to US exceptionalism and anti-imperialism (O'loughlin, 1999)-a notion of protection through geographical isolation has long informed the US approach to its international affairs. For the US, the merits of this approach are evidenced by the global hegemony it has enjoyed. Through strategic alliances and partnerships that have offset military threats and advanced the US economy, for several decades, the US has sustained a position of global economic and military dominance (Alcaro, 2018).

The rise of China in the global world order represents a threat to US hegemony (Alcaro, 2018). This is, of course, a simplification of a complex relationship that also features 'pathological codependency' due in significant part to enduring macroeconomic imbalances resulting from China's foreign exchange reserves of US currency (Roach, 2014). Nevertheless, the relationship between the US and China is evolving and China's growth can be viewed as destabilising to longstanding US geopolitical strategy. In geopolitics, military and economic capacity are key indices of power (Flint, 2016). But geopolitical power is also relational; military and economic capacities "only have an effect when two actors form a power relation" 
(Flint, 2016, p.16), whether that be a relationship of alliance or competition. In recent years, China has greatly improved its economic and military capacities resulting in increasingly competitive power relations between the US and China (Xuetong, 2020). While geopolitical relations between the two nations are complex, China's continuing accumulation of power challenges a world order that is shaped to best serve US interests.

The TikTok controversy falls within an intensifying contest between the US and China over the strategic value of the digital environment (Cartwright, 2020). The geopolitics of the digital environment, and of platforms more specifically, involves contestation over who gets to extract economic value from the platform economy (Cartwright, 2020); who gets to set laws and norms for and exert ideological influence through vast sociotechnical systems (DeNardis \& Hackl, 2015; Tusikov, 2019); and who enjoys the strategic political power derived from control over or access to digital data and infrastructure (Mann \& Warren, 2018). Up to this point, this realm of geopolitics has largely mirrored that of the physical environment-the US has dominated economically and culturally across large regions of the digital environment (Gray, 2020). Recently, however, Chinese technology firms have flourished (Hong, 2017), expanding China's economic and strategic capacities and sparking competitive tensions with the US (Cartwright, 2020). As the economic value of the digital environment continues to grow, we can expect to see more contests between nations seeking to extract value and exert influence in the digital environment; and identifying the geopolitical underpinnings of ensuing platform controversies is important for an effective evaluation of the related legal or public policy interventions. As Sickler explains, viewing "the world in which we live from a geopolitical and geostrategic perspective is important...because it can help make clear what the real stakes are in such issues and thus enable the public to assess the choices taken by the government in its name" (Sicker, 2010, pp. 17-18). By placing the recent contestation over TikTok within its geopolitical context, we improve understanding of key political motivations driving this platform controversy and the resulting policy responses.

\section{The geopolitics of TikTok's controversial rise in the US}

In the short form video market, while apps such as Marco Polo and House Party have provided alternatives to market leaders Instagram, Snapchat and Facebook, only TikTok has managed to achieve a level of adoption high enough to pose an actual competitive threat to the market incumbents. TikTok rose to prominence in 
2019 and, by early 2020, it was the most downloaded app globally (Williams, 2020), surpassing 2 billion downloads in the Google Play and App Store combined (Moshin, 2020). In 2021, TikTok is estimated to have over 700 million active monthly users worldwide (Datareportal, 2021).

TikTok is the product of technology developer ByteDance Ltd, a company born in China but incorporated in the Cayman Islands and notable for not being part of the three tech giants in China-Baidu, Alibaba and Tencent. In 2016, ByteDance brought its short video platform to the Chinese market as Douyin. A year later, the company acquired Musical.ly-a lip synching platform, also created in China, which had some limited success among teenagers in the US (Spangler, 2016). In 2018, ByteDance integrated Musical.ly with Douyin technology to produce TikTok, a product designed specifically for a global audience (Jia \& Ruan, 2020). TikTok hosts audiovisual works between 15-60 seconds, algorithmically curated for audiences, with features designed to instigate user generated content and virality (Kaye et al., in press).

TikTok's success is due in significant part to its innovative recommendation system (Chan, 2018). TikTok's machine learning-enabled recommendation system does not require users to follow creators or to explicitly opt-in to certain types of content. Instead, the platform decides what to serve its users as they swipe through a never-ending stream of short videos (TikTok Newsroom, 2020a). To determine which videos it serves each user, TikTok reportedly uses three key algorithms: a recommendation algorithm, a content classification algorithm, and a user profiling algorithm (C. Wang, 2020). The recommendation algorithm reportedly uses real-time training and learns from features such as correlation between content and user information, user behaviour and trends (C. Wang, 2020). TikTok also provides all videos that pass an initial screening process exposure to at least 200 users, giving a wide range of content creators an opportunity for virality, but also providing TikTok with vast troves of user and video data that it can feed into its algorithms. With TikTok, Bytedance has successfully harnessed machine learning systems to provide an innovative short video platform experience.

Despite its large and enthusiastic global user base, TikTok has been the subject of intense criticism and speculation about the ethics of the platform, its objectives and its sociocultural implications. The platform has been accused of excessive data extraction and analysis practices, including unnecessarily copying data from users' phones (Al-Heeti, 2020) and collecting information that may be used to identify and track the location of users (Misty Hong v Bytedance Inc, 2019). TikTok has also been subject to claims that it hosts harmful content; for example, in July 2020, the 
BBC reported that extremist libertarian groups in the US had a substantial presence on the platform (Clayton, 2020). At the same time, others argue TikTok unfairly exploits user content and copyrighted works without sufficient economic return for creators and intellectual property owners (Alexander, 2020). Yet, most of the issues at the heart of these criticisms are not unique to TikTok or new to the short form video economy. They are reflective of the well established politics of platforms, which feature controversies over data security and user privacy (Isaak \& Hanna, 2018), content moderation (Gillespie, 2018), and the regulation of speech (Balkin, 2017). YouTube, Facebook, Google, Twitter, Instagram and other US platforms have been subject to criticisms and controversies similar to those surrounding TikTok (Suzor, 2019). What the TikTok controversy reveals is the extent to which the politics of platforms is immersed in geopolitical tensions between the US and China.

The geopolitical tensions underpinning the TikTok controversy are reflected most strongly in the debates over TikTok's national security implications. On 24 June 2020, national security advisor to the US government, Robert O'Brien, spoke at the Arizona Commerce Authority on the topic of the Chinese government's "ideological and global ambitions" (O’Brien, 2020). In his speech, O'Brien warned that China posed a threat to US citizens and he directly implicated TikTok in his critique:

On TikTok, a Chinese-owned social media platform with over 40 million American users-probably a lot of your kids and younger colleagues-accounts criticizing CCP policies are routinely removed or deleted...When the Chinese Communist Party cannot buy your data, it steals it...How will the Chinese Communist Party use this data? In the same way it uses data within China's borders: to target, to flatter, to cajole, to influence, to coerce, and to even blackmail individuals to say and do things that serve the Party's interests (O’Brien, 2020, para. 22).

While the Chinese government has been known to influence the content available on Douyin, the evidence of similar influence on TikTok is limited. For example, a 2020 comparative study of the two Bytedance short form video apps found the Chinese government used Douyin to promote Chinese patriotism but there was no corresponding evidence on TikTok (Chen et al., 2020). When Bytedance first began releasing TikTok into markets outside of China in 2017, the platform's content moderation guidelines were aimed at limiting the circulation of all highly controversial materials on the platform. In some cases, this resulted in censorship of content unfavourable to the Chinese state, including videos relating to Tibetan inde- 
pendence and the treatment of Uighurs in Xinjiang (Hern, 2019). But TikTok's approach to content moderation has evolved (TikTok Newsroom, 2019), and a range of political activists are now prominent on the platform (Andrews, 2020). While TikTok is often praised for facilitating access to diverse creators and content (see, e.g., Yan, 2020) it also continues to be criticised for algorithmically suppressing political videos, such as those from Black Lives Matter activists (McCluskey, 2020). Currently, there is a lack of robust evidence for measuring and evaluating the extent to which TikTok's algorithms meaningfully promote politically and socially diverse content, but what does seem clear from the available evidence (e.g., Chen et al, 2020; Zhang 2020) is that TikTok is not subject to Chinese state influence to the same extent as is Douyin.

The lack of a robust evidence-base notwithstanding, in his speech, O'Brien was explicit about the ideological and security implications of TikTok, and its relationship to US geopolitical strategy:

\footnotetext{
President Trump understands that lasting peace comes through strength ... The Trump Administration will speak out and reveal what the Chinese Communist Party believes, and what it is planning - not just for China and Hong Kong and Taiwan, but for the world... Together with our allies and partners, we will resist the Chinese Communist Party's efforts to manipulate our people and our governments, damage our economies, and undermine our sovereignty. (O'Brien, 2020, para. 47).
}

On 6 July 2020, US Secretary of State, Mike Pompeo, confirmed the Trump administration was considering banning TikTok on national security grounds (Bella, 2020). Pompeo expressed that TikTok might pose a national security threat if Bytedance were compelled to provide information about US citizens to the Chinese government and implied TikTok should be treated similar to Huawei, the Chinese telecommunications company that is effectively banned in the US (Keane, 2020). Evidently, it was the Trump administration's position that TikTok is not simply a platform for connection and entertainment but a tool the Chinese state might wield for strategic security and ideological influence within the US. In other words, TikTok might be used to further empower China in geopolitical relations between the two states.

TikTok's data policies and practices provide no indication that the platform poses any singular national security threat and compared to other popular Chinese mobile applications it has higher standards of user data privacy protections (Jia \& Ru- 
an, 2020). The company also has a formal policy to deal with requests for user information made by governments. TikTok's policy provides that TikTok will honour requests for user information that are made through "proper channels and where otherwise required by law" or "in limited emergency situations...without legal process" to prevent deaths or serious injury (TikTok Safety Centre, 2020a, Compliance with government requests section). TikTok's law enforcement guidelines further clarify that proper process includes providing "the appropriate legal documents required for the type of information being sought, such as a subpoena, court order, or warrant, or submit an emergency request" (TikTok Law Enforcement, 2020, TikTok's policy on responding to law enforcement requests section). Both Facebook and Google have similar policies for handling requests for user information made by governments (Facebook, 2019; Google Inc., 2020).

Since December 2019, TikTok has released to the public aggregated data on the requests for user information made to TikTok by governments from around the world (Ebenstein, 2019). According to 2019 and 2020 reports, TikTok has not received any requests from the Chinese government and the majority of requests for user information received between 1 July 2019 and 31 December 2020 were made by India and the United States (TikTok Safety Centre, 2020b). It is beyond the scope of this research to determine whether TikTok's reports are wholly accurate, however, they broadly follow the standards of reporting that Google and Facebook provide in their transparency reports (Facebook, 2019; Google Inc., 2020). It is also notable that a $2020 \mathrm{CIA}$ assessment of TikTok reportedly concluded that while it was possible that the Chinese government could intercept TikTok data, there was no evidence to suggest that it had in fact done so (Sanger \& Barnes, 2020). From the available evidence, it appears that the potential for the Chinese government to use TikTok data to threaten US national security remains theoretical.

The national security concerns expressed by the US government-most specifically the concern that TikTok user data may be accessed by the Chinese government and used to track and gather information on US citizens and companies-raise an interesting issue of territoriality. Over the past few years, Bytedance has extended its operations well beyond Chinese territorial spaces. While Bytedance Ltd was founded in China, it is incorporated outside of China, in the Cayman Islands, and it operates as a multinational organisation, with subsidiaries in the US, Australia, Singapore and the UK (Bytedance, 2020). TikTok operates from across the US, Europe and Asia with its largest US offices in Los Angeles, Mountain View and New York (Shead, 2020). In 2020, TikTok reportedly had almost 1,400 US employees (McGill, 2020). To use TikTok for the surveillance of US citizens (a key concern stated by US 
officials) the Chinese state would either need to do so without TikTok's permission (as it might seek to do with any company) or it would need to compel Chinese or US TikTok employees to provide access to its operations within the US. While neither course of action is inconceivable, and indeed TikTok's multinational structure may make it more strategically useful to the Chinese state (Cartwright, 2020), the Chinese origins of TikTok can be used to overstate or oversimplify the platform's actual territorial connection to China.

Notably, when new national security laws were introduced in Hong Kong in 2020-laws that may have subjected TikTok to China's National Intelligence regime which require organisations to cooperate with Chinese intelligence agencies-TikTok suspended the app's operation there (Wang, 2020). In this case, TikTok took overt action to stay out of the jurisdictional reach of the Chinese government.

Since its rise in the international digital platform market, TikTok has attempted to establish a reputation as a secure and transparent global corporate citizen. In April 2020, in an update on TikTok's security policies and practices, Roland Cloutier, TikTok's Chief Security Officer, explained that the company had "engaged with the world's leading cyber security firms to accelerate our work advancing and validating our adherence to globally recognized security control standards" and continued to limit "the number of employees who have access to user data and the scenarios where data access is enabled" (Cloutier, 2020a, para. 15). Cloutier further explained his goal was to "minimize data access across regions so that, for example, employees in the APAC region, including China, would have very minimal access to user data from the EU and US" (Cloutier, 2020a, para. 7). In late June 2020, TikTok announced that it had established offices in Los Angeles and Washington, DC dedicated to giving "lawmakers and experts the opportunity to look under the hood of TikTok" (Cloutier, 2020b, para. 2). At these centres, the access TikTok provides includes access to the source code of its algorithms, a practice that stands TikTok apart from most other platforms in the US digital platform market. Former TikTok CEO, Kevin Mayer, explained TikTok's desire to be a market leader in transparency and encouraged other platforms to make similar disclosures (Mayer, 2020). In the midst of increasingly hostile rhetoric from the US government, TikTok has publicly given the appearance of working enthusiastically on its security, transparency and accountability credentials.

While openly rejecting the security claims made against it, TikTok has also sought to redirect political discourse towards competition in the digital platform market. In late July 2020, TikTok released a statement arguing that competition drives innovation and that it was "unfortunate for creators, brands, and the broader com- 
munity that it has been years since a company came along and reimagined what a social entertainment platform could be" (Mayer, 2020, para. 1). TikTok's then CEO, Kevin Mayer, also urged the US government to consider the benefits of "fair and open competition" and pointed to "maligning attacks by our competitor-namely Facebook-disguised as patriotism and designed to put an end to our very presence in the US" (Mayer, 2020, para. 7). As reported by the Wall Street Journal, in 2019, Mark Zuckerberg, CEO of Facebook, conducted a series of meetings with US politicians, including US Senators and President Donald Trump, in which he argued TikTok posed a serious economic threat to the US (Wells et al., 2020). For TikTok executives, the controversy over its rise internationally is an issue of market competition and TikTok considers its US counterparts to be seeking to leverage their relationship with US lawmakers (Birnhack \& Elkin-Koren, 2003) to protect their dominance in a highly lucrative international digital platform market.

TikTok has also tried to use the criticisms of its data practices to initiate a discussion of the problems of transparency and accountability present in the international digital platform market at large. TikTok has suggested that rather than focusing narrowly on TikTok's Chinese ties: "the bigger move is to use this moment to drive deeper conversations around algorithms, transparency, and content moderation, and to develop stricter rules of the road" (Mayer, 2020, para. 11). Mayer stated that he accepted the scrutiny the company received based on its Chinese origins and embraced "the challenge of giving peace of mind through greater transparency and accountability...Even more, we believe our entire industry should be held to an exceptionally high standard" (Mayer, 2020, para. 5). It is unclear whether these statements reflect a genuine commitment by TikTok. They may simply be an offensive rhetorical tactic in an ongoing political battle. Nonetheless, it appears TikTok has attempted to leverage the scrutiny over its data policies and practices to initiate a broader debate about the politics of platforms and the problems inherent to almost all market participants.

Despite TikTok's actions and rhetoric, on 31 July 2020, President Trump confirmed that he was indeed intending to ban TikTok in the US (Trump, 2020a). Several days later, Microsoft released a statement explaining that its representatives had spoken to President Trump directly regarding the acquisition of TikTok (Microsoft, 2020). Microsoft also confirmed that it was in discussions with ByteDance and that any acquisition would include a term ensuring all US user data is stored only in the US (Microsoft, 2020). Speaking about his conversations with Microsoft, President Trump stated, “it can't be controlled, for security reasons, by China. Too big, too invasive, and it can't be" (Trump, 2020b, para. 451). Trump also commented 
that he wanted "no security problems with China. It's got to be an American company. It's got to be American security. It's got to be owned here" (Trump, 2020c, para. 91). For the Trump administration, regardless of any enhanced transparency by TikTok or the benefits of increased competition in the US digital platform market, TikTok was to be treated as a Chinese asset, one that could be leveraged to enhance Chinese state power in relation to the US.

On 3 August 2020, Chinese Foreign Ministry Spokesperson, Wang Wenbin, commented that the US government's involvement in the negotiations between Microsoft and ByteDance was a "violation of market economy rules" and he called on the US to "stop politicizing economic and trade issues, and stop practicing discriminatory and exclusive policies in the name of national security" (Wenbin, 2020a, paras. 5-6). On 4 August 2020, Wenbin added "it is nothing new for the US to use its state machine to suppress foreign companies" (Wenbin, 2020b, para. 34). In its response, China sought to position the US government's rhetoric and actions over TikTok as an act of economic nationalism. Certainly, the intervention by a US President to force the sale of a private company stands at odds with principles of free market capitalism, and the Trump administration may have been motivated in some part by a desire to protect a thriving American industry. Yet, both states have more to gain in this contest than economic benefits alone. The US position on TikTok falls within a broader contest over the strategic capacities at play in the digital environment and within a broader set of policy objectives.

On 5 August 2020, the US Department of State announced an expansion of its Clean Network programme, which has the stated objective of "guarding our citizens' privacy and our companies' most sensitive information from aggressive intrusions by malign actors, such as the Chinese Communist Party (CCP)" (Pompeo, 2020, para. 1). Expansions to the programme included five new policies aimed explicitly at reducing the presence of China in the US, by limiting the use of Chinese providers of telecommunication carriers, applications sold in app stores and preinstalled on devices, cloud services, and undersea cables. When discussing the expanded programme Pompeo called for its "allies and partners in government and industry around the world to join the growing tide to secure our data from the CCP's surveillance state and other malign entities" (Pompeo, 2020, para. 5). In keeping with its strategy of offshore balancing, the Trump administration sought to leverage its global alliances and partnerships to limit the growth of Chinese companies in the digital environment; as with, for example, Huawei, which the Trump administration pressured allies to ban (successfully so in the case of the UK and Canada where Huawei has been stopped from providing $5 \mathrm{G}$ network infra- 
structure) (Ljunggren, 2020; Baker \& Chalmers, 2020).

The following day, the Trump administration issued an executive order aimed at forcing the sale of TikTok to a US company (Trump, 2020d). It did so by prohibiting transactions with Bytedance by any person in the US after 45 days from the issue of the executive order. The order specified that the prohibition was necessary in the context of a national emergency relating to "the spread in the United States of mobile applications developed and owned by companies in the People's Republic of China" (Trump, 2020d, para. 2). The order posited that TikTok posed a threat to "the national security, foreign policy, and economy of the United States" and that TikTok's data collection might allow the Chinese government "access to Americans' personal and proprietary information-potentially allowing China to track the locations of Federal employees and contractors, build dossiers of personal information for blackmail, and conduct corporate espionage" (Trump, 2020d, para. 3). A similar order was issued against the Chinese company Tencent Holdings Ltd which owns the messaging app WeChat (Trump, 2020e). On 14 August 2020, the Trump administration announced a second executive order requiring Bytedance to divest from TikTok on the grounds that a review by the US Committee on Foreign Investment found credible evidence to suggest that Bytedance's acquisition of Musical.ly posed a threat to US national security (Trump, 2020f).

Responding to the actions taken against it by the Trump administration, TikTok argued there was no evidence to support the administration's position and the executive orders lacked due process (TikTok Newsroom, 2020b). The company explained that it had tried to engage in good faith negotiations to address security concerns but the US government "paid no attention to facts, dictated terms of an agreement without going through standard legal processes, and tried to insert itself into negotiations between private businesses" (TikTok Newsroom, 2020b, para. 2). TikTok asserted that the executive order showed the US government was relying on "unnamed "reports" with no citations, fears that the app "may be" used for misinformation campaigns with no substantiation of such fears, and concerns about the collection of data that is industry standard for thousands of mobile apps around the world" (TikTok Newsroom, 2020b, para. 3).

The Chinese government similarly voiced opposition to the executive orders. In support of TikTok, China's Foreign Ministry Spokesperson, Zhao Lijian, called for the US to "correct its hysterical and wrong actions, come back to market principles and WTO norms, and stop unjustified suppression and discriminatory restriction targeting Chinese companies" (Lijian, 2020a, para. 53). Spokesperson Lijian also emphasised the strong foundations TikTok already has in the US, pointing to the 
senior TikTok staff who are US citizens, TikTok's US operations including company servers and data centres, and hundreds of American employees (Lijian, 2020b). Lijian argued that US national security concerns were unfounded and the US was acting in contravention of free market principles and international trade laws:

even a CIA assessment says there's no evidence that China intercepted TikTok data or used the app to bore into cell phones. A think-tank in the US also said that there is no security justification for banning an app merely because it is owned by a Chinese company. This proves once again that "freedom and security" is nothing more than an excuse for some US politicians to pursue gunboat diplomacy in the digital age. Such bullying practices are a flagrant denial of the principles of market economy and fair competition, of which the US is a self-claimed "champion". (Lijian, 2020b, para. 13)

China also called for the US to reverse its executive orders (Lijian, 2020b), but, in late August, it announced new technology export rules that apply to artificial intelligence technology which may limit Bytedance's capacity to sell TikTok's machine learning algorithms. The Chinese government advised TikTok to "seriously and cautiously" review the rules and consider their implication for the intended US sale (Xiao \& Lin, 2020, para. 5). In effect, China retaliated against the US with its own policy intervention aimed at spoiling negotiations over the sale of TikTok to a US firm.

This snapshot of the controversy over TikTok's rise in the US provides a useful case study in the current geopolitics of platforms which is in large part defined by shifts in the world order caused by the economic rise of China and its implications for US hegemony. Essentially, TikTok has found itself in the middle of a contest between two nations over the strategic and economic value of the digital environment. Certainly, in 2020 TikTok was also at the whim of an idiosyncratic and highly transactional US President who may have been motivated by personal misgivings against TikTok (Lorenz et al., 2020), a desire to unconventionally profit from its sale (Davidson, 2020) and his particular view of the US-China economic relationship (Mason et al., 2020). Nonetheless, the Trump administration's actions and rhetoric towards TikTok are consistent with a geopolitical analysis which suggests that regardless of specific leaders or foreign policy approaches, since the end of the Cold War, the US has pursued a hegemonic geopolitical strategy informed by its "territorial nation-state identity" (Sharp, 2000, p. 332) defined by its geographical isolation and capacity to undertake offshore balancing. In other words, there is a logic that underlies the US government's view of TikTok, as evidenced by policymakers 
such as Pompeo and O'Brien, that is consistent with many decades of US geopolitical strategy. In the game of platform geopolitics, as China has begun to amass information and communication capacities (Hong, 2017; Thussu, 2018), the US is taking strategic policy action to preserve its advantages.

To be sure, China can not claim any high road in this geopolitical contest. In 2018, China forced Apple to move data about Chinese citizens to data centres located in China and certain US technology companies are completely banned from operating there (O'Hara \& Hall, 2018). Indeed, both nations have a history of sustaining protectionist policies aimed at shielding strategically important industries (Lenway et al., 1996). By no means are China and the US the only states participating in the geopolitics platforms; the European Union, for example, recently issued a paper exploring the potential for greater 'digital sovereignty' for that region (Madiega, 2020) and in 2020 India banned TikTok and 58 other apps on the grounds that they were a "threat to sovereignty and integrity of India" (Press Information Bureau Delhi, 2020).The geopolitics of the digital environment is multifaceted. And yet, once we recognise the geopolitical motivations underpinning a platform controversy such as this, the harder challenge is working out how to move beyond conventional geopolitical bounds-neither US nor Chinese hegemony in the digital environment is ideal or inevitable-and there are other important policy considerations relevant to this platform controversy.

\section{Digital platform competition: imagining a world order for the digital environment unbound from conventional geopolitics}

TikTok provides significant competition to the US platform incumbents. But, so far, the US government has opted to explicitly focus on the geopolitical implications of TikTok, rather than the implications for the US digital platform market. Whether the Biden administration will take a similar approach to that of the Trump administration remains to be seen. Importantly though, TikTok's willingness to increase transparency beyond current industry standards indicates that, when pressed, platforms can adapt in areas such as security, transparency and accountability. TikTok's immense global user base also indicates the willingness of consumers to adopt products regardless of their country of origin. If real competition and user choice were to increase, requiring the incumbent platforms to compete for users more actively, we might see further innovations in the digital platform market and a dilution of the concentrated private power wielded by the incumbent market actors (Ghosh \& Couldry, 2020). 
Free market economic theory suggests competition will occur if markets are free from government regulation and other state interventions, under the assumption of a level playing field for all market participants (Harvey, 2007). But, in the digital platform market, there are embedded companies who enjoy advantages from economies of scale and high barriers to entry, often resulting from vast and selfperpetuating data stores (Pasquale, 2015; Plantin et al, 2016). Under these conditions, competition is unlikely to spontaneously occur. In recent years, scholars have proposed a range of pathways for improving competition in digital platform markets (see e.g. Burdon, 2020; Daly, 2016; Flew et al., 2019; Khan, 2016, 2019; Svantesson, 2017; Winseck, 2020). Following these scholars and, more recently, certain policymakers (see e.g. Australian Competition and Consumer Commission, 2019, 2021; European Commission, 2020; Favaro Corvo Ribas \& Maximiano Munhoz, 2020; Utsunomiya \& Takamiya, 2020), two types of market reform interventions appear particularly urgent: antitrust measures including breaking up vertically and horizontally integrated firms and the effective application of rules that limit the expansion of market incumbents through mergers and acquisitions; and the widespread adoption of data portability and interoperability standards that meaningfully address power asymmetries and barriers to entry into data-driven markets.

Geopolitical forces have the potential to both aid and hinder platform market reform agendas, depending on the nature and level of international cooperation (van Dijck et al., 2018). Successfully regulating companies with transnational operations, such as Facebook, Google and Amazon, is likely to require substantial international cooperation. Recently, Winseck and Puppis (2020) collated over 88 different platform regulation inquiries, reviews and proceedings undertaken in jurisdictions around the world between 2016 and 2020. A high number of regulatory initiatives globally suggests a high level of willingness among lawmakers globally to address the problems created by market concentration in the digital economy, yet so far there has not been a coordinated global regulatory undertaking. Any such undertaking would inevitably require confronting the countervailing force of digital nationalism (Mann \& Daly, 2020; Pohle \& Thiel, 2020). A challenge for interested researchers and policymakers is the pursuit of an agenda that will incentivise nation-states from around the globe to overcome nationalistic impulses and economic protectionism, in order to realise the benefits of competition, innovation, and the decentralisation of power in the digital economy.

The dilution or dispersal of geopolitical power derived from the digital economy would require competitive market participants from more countries than the US 
and China. In addition to market reforms, this objective could be supported by national digital infrastructure and investment programmes aimed at growing domestic platform economies. Specific programmes would need to be tailored to suit national economies, taking into account economic conditions, existing resources, and industry capacities, but undoubtedly, they must extend beyond microeconomic investments such as industry grants or start-up incubators. To spur innovation, policymakers must think big; at the scale of, for example, high speed rail programmes; national highway projects; or national broadband initiatives (Winseck, 2020).

More work is required to identify the most viable pathways for achieving a competitive international digital platform market and avoiding the solidification of conventional geopolitical power dynamics within the digital environment. To summarise, a research agenda with this goal might comprise the following streams of inquiry:

1. How can nation-state collaboration in the regulation of platforms be extended, beyond existing multilateral and regional undertakings, to achieve a globally coordinated regulatory approach to market reforms for greater platform competition?

2. How might growing international consensus about the need for interventions to reduce concentrated private power be reconciled with digital nationalism, with a view to achieving a more decentralised digital environment?

3. What types of national infrastructure and investment programmes could a state implement, complementing market reforms, to support emerging digital platforms to overcome existing barriers to entry into markets nationally and internationally?

Ambitious legal, economic, and technical policy undertakings are politically difficult, but they should not be relegated to the theoretical. China is acting on at least two of these policy fronts. The China Standards 2035 industry policy plan is expected to outline an agenda to enable China to set the technical standards for the future development of advanced technological systems including artificial intelligence, the Internet of Things, and $5 \mathrm{G}$ internet (Kharpal, 2020). This plan is expected to work in concert with the country's Belt and Road Initiative, through which China is investing in infrastructure and trade corridors throughout Eurasia and other nearby regions (Koyt, 2020), and will be used to export Chinese technical standards (Cai, 2017). For those concerned about the future distribution of power in the digital environment, now is the time to take up the challenge of devising innovative and ambitious policy programmes. 


\section{Conclusion}

On the basis of its data policies and practices, TikTok poses no greater security threat to its users than do its counterparts. Almost all of the most widely used digital platforms threaten the privacy and security of users, they all have the capacity for immense ideological influence, and they exploit user data for economic gain. As a geopolitical analysis makes clear, TikTok has found itself in the middle of a contest over the value of the digital environment and the US is eager to preserve the economic and strategic advantages it has enjoyed for several decades. In many ways, though, this is a familiar economic story: market incumbents striving to sustain their privileged positions, policymakers seeking to protect strategically important industries. But, if policymakers were to embrace platform competition, rather than rejecting it along conventional geopolitical grounds, there is potential for greater innovation and a dilution of the concentration of power in the international platform market. Achieving a competitive market, and eschewing conventional geopolitical power dynamics, is a monumental challenge. It will require highly ambitious public policy interventions. But it is a challenge worth taking up. The concentration of private power in the digital environment diminishes democratic societies and we should seek solutions that look beyond both US and Chinese hegemonic power.

\section{ACKNOWLEDGEMENT}

The author wishes to thank the following people for their valuable feedback on earlier drafts of this paper: editors Frédéric Dubois and Angela Daly, reviewers Lotus Ruan and Madison Cartwright, Mark Burdon, Bondy Kaye, Huon Curtis, Ariadna Matamoros Fernandez, Nic Suzor, Jean Burgess and Dipayan Ghosh.

\section{References}

Alcaro, R. (2018). The Liberal Order and its Contestations. A Conceptual Framework. The International Spectator, 53(1), 1-10. https://doi.org/10.1080/03932729.2018.1397878

Alexander, J. (2020, August 2). TikTok's a year old, when will its creators make money? The Verge. htt ps://www.theverge.com/2019/8/2/20748770/tiktok-monetization-youtube-anniversary-twitch-face book-creators

Al-Heeti, A. (2020, June 26). IOS 14 drives TikTok to stop grabbing info from users' clipboards, report says. CNET. https://www.cnet.com/news/ios-14-drives-tiktok-to-stop-grabbing-info-from-use rs-clipboards-report-says/ 
Andrews, P. C. (2020, June 2). How TikTok got political. The Conversation. http://theconversation.co m/how-tiktok-got-political-139629

Australian Competition and Consumer Commission. (2017, December 4). ACCC Commences Inquiry into Digital Platforms [Press release]. Australian Competition and Consumer Commission. https://ww w.accc.gov.au/media-release/accc-commences-inquiry-into-digital-platforms

Australian Competition and Consumer Commission. (2019). Digital platforms inquiry. https://www.ac cc.gov.au/system/files/Digital\%20platforms\%20inquiry\%20-\%20final\%20report.pdf

Australian Competition and Consumer Commission. (2021, March 11). Feedback sought on choice and competition in internet search and web browsers [Press release]. Australian Competition and Consumer Commission. https://www.accc.gov.au/media-release/feedback-sought-on-choice-and-co mpetition-in-internet-search-and-web-browsers

Baker, L., \& Chalmers, J. (2020). As Britain bans Huawei, U.S. https://www.reuters.com/article/us-brita in-huawei-europe-idUSKCN24F1XG

Balkin, J. M. (2017). Free speech in the algorithmic society: Big data, private governance, and new school speech regulation. UCDL Rev, 51, 1149.

Bella, T. (2020). Pompeo says the U.S. is 'certainly looking at' banning TikTok and other Chinese apps. Washington Post. https://www.washingtonpost.com/nation/2020/07/07/tiktok-ban-china-usapompeo/

Birnhack, M. D., \& Elkin-Koren, N. (2003). The Invisible Handshake: The Reemergence of the State in the Digital Environment. Va. JL \& Tech, 8, 6-13. https://doi.org/10.2139/ssrn.381020

Burdon, M. (2020). Digital Data Collection and Information Privacy Law. Cambridge University Press.

Cai, P. (2017). Understanding China's Belt and Road Initiative. Think-Asia, Lowy Institute For International Policy.

Cartwright, M. (2020). Internationalising state power through the internet: Google, Huawei and geopolitical struggle. Internet Policy Review, 9(3). https://doi.org/10.14763/2020.3.1494

Centre, T. S. (2020a). Safety Center-Resources | TikTok. https://www.tiktok.com/safety/resources/trans parency-report?lang=en\&appLaunch=

Centre, T. S. (2020b). TikTok Transparency Report. https://www.tiktok.com/safety/resources/transpare ncy-report?lang=en \&appLaunch=

Chan, C. (2018). When Al is the Product: The Rise of Al-Based Consumer Apps. Andreessen Horowitz. https://a16z.com/2018/12/03/when-ai-is-the-product-the-rise-of-ai-based-consumer-apps/

Chen, X., Kaye, D. B., \& Zeng, J. (2020). \#PositiveEnergy Douyin: Constructing 'Playful Patriotism' in a Chinese Short-Video Application. Chinese Journal of Communication. https://doi.org/10.1080/17544 750.2020 .1761848

Clayton, J. (2020). TikTok's Boogaloo extremism problem. BBC News (Online. https://www.bbc.com/n ews/technology-53269361

Cloutier, R. (2020a). Our approach to security-Newsroom | TikTok. https://newsroom.tiktok.com/en-u s/our-approach-to-security

Cloutier, R. (2020b). TikTok's security and data privacy roadmap-Newsroom | TikTok. https://newsroo m.tiktok.com/en-us/tiktoks-security-and-data-privacy-roadmap 
Cloutier, R. (2020c). Updates on our security roadmap-Newsroom | TikTok. https://newsroom.tiktok.co m/en-us/updates-on-our-security-roadmap

Commission, E. (2020). The Digital Markets Act: Ensuring fair and open digital markets [Text. European Commission. https://ec.europa.eu/info/strategy/priorities-2019-2024/europe-fit-digital-ag e/digital-markets-act-ensuring-fair-and-open-digital-markets_en

Daly, A. (2016). Private Power, Online Information Flows and EU Law: Mind the Gap. Hart.

Datareportal. (2021). Global Social Media Stats. DataReportal - Global Digital Insights. https://datar eportal.com/social-media-users

Davidson, H. (2020). TikTok sale: Trump approves Microsoft's plan but says US should get a cut of any deal. The Guardian. https://www.theguardian.com/technology/2020/aug/03/tiktok-row-trump-to-tak e-action-soon-says-pompeo-as-microsoft-pursues-deal

DeNardis, L., \& Hackl, A. M. (2015). Internet Governance by Social Media Platforms. Telecommunications Policy, 39(9), 761-770. https://doi.org/10.1016/j.telpol.2015.04.003

Donzelli, G., Palomba, G., Federigi, I., Aquino, F., Cioni, L., Verani, M., Carducci, A., \& Lopalco, P. (2018). Misinformation on vaccination: A quantitative analysis of YouTube videos. Human Vaccines \& Immunotherapeutics, 14(7), 1654-1659. https://doi.org/10.1080/21645515.2018.1454572

Ebenstein, E. (2019, December 31). Our first Transparency Report. TikTok Newsroom. https://newsroo m.tiktok.com/en-us/our-first-transparency-report

Facebook. (2019). Requests For User Data. https://transparency.facebook.com/government-data-requ ests

Favaro Corvo Ribas, G., \& Maximiano Munhoz, N. (2020, October 26). The Brazil Antitrust Agency's new study on digital markets. International Bar Association. https://www.ibanet.org/Article/NewDeta il.aspx?ArticleUid=48D83F91-8874-4F3B-8FCF-E85A384BA841

Flew, T., Martin, F., \& Suzor, N. (2019). Internet Regulation as Media Policy: Rethinking the Question of Digital Communication Platform Governance. Journal of Digital Media \& Policy, 10(1), 33-50. http s://doi.org/10.1386/jdmp.10.1.33_1

Flint, C. (2016). Introduction to Geopolitics (3rd ed.). Taylor and Francis. https://doi.org/10.4324/9781 315640044

Fowler, G. (2020, July 13). Is it time to delete TikTok? A guide to the rumors and the real privacy risks. The Washington Post. https://www.washingtonpost.com/technology/2020/07/13/tiktok-privac y/

Ghosh, D., \& Couldry, N. (2020). Digital Realignment: Rebalancing Platform Economies from Corporation to Consumer (Working Paper No. 155; Mossavar-Rahmani Center for Business and Government).

Gillespie, T. (2010). The politics of 'platforms'. 12(3), 347-364. https://doi.org/10.1177/14614448093 42738

Gillespie, T. (2018). Custodians of the Internet: Platforms, Content Moderation, and the Hidden Decisions that Shape Social Media. Yale University Press.

Google Inc. (2020). Google Transparency Report. https://transparencyreport.google.com/?hl=en

Gray, J. (2020). Google Rules: The History and Future of Copyright Under the Influence of Google. Oxford 
University Press.

Harvey, D. (2007). A Brief History of Neoliberalism. Oxford University Press.

Hern, A. (2019). Revealed: How TikTok censors videos that do not please Beijing. The Guardian. http://w ww.theguardian.com/technology/2019/sep/25/revealed-how-tiktok-censors-videos-that-do-not-ple ase-beijing

Hong, Y. (2017). Networking China: The Digital Transformation of the Chinese Economy. University of Illinois Press. https://doi.org/10.5406/illinois/9780252040917.001.0001

Isaak, J., \& Hanna, M. J. (2018). User data privacy: Facebook, Cambridge Analytica, and privacy protection. Computer, 51(8), 56-59. https://doi.org/10.1109/MC.2018.3191268

Jia, L., \& Ruan, L. (2020). Going global: Comparing Chinese mobile applications' data and user privacy governance at home and abroad. Internet Policy Review, 9(3). https://doi.org/10.14763/202 0.3.1502

Kaye, B., Rodriguez, A., Langton, K., \& Wikstrom, P. (In press). You Made This? I Made This: Practices of Authorship and (Mis)Attribution on TikTok. International Journal of Communication.

Keane, S. (2020, September 11). Huawei ban timeline: Chinese company's Harmony OS may hit phones next year. CNET. https://www.cnet.com/news/huawei-ban-full-timeline-us-restrictions-chin a-trump-android-google-ban-harmony-os/

Kelly, P. (2006). A Critique of Critical Geopolitics. Geopolitics, 11(1), 24-53. https://doi.org/10.1080/1 4650040500524053

Khan, L. (2019). The Separation of Platforms and Commerce. Columbia Law Review, 119(4), 973-1098. https://columbialawreview.org/wp-content/uploads/2019/05/Khan-THE_SEPARATION_O F_PLATFORMS_AND_COMMERCE-1.pdf

Khan, L. M. (2016). Amazon's antitrust paradox. Yale Law Journal, 126(3), 710-805. https://digitalco mmons.law.yale.edu/ylj/vol126/iss3/3/

Kharpal, A. (2020, April 27). Power is "up for grabs": Behind China's plan to shape the future of nextgeneration tech. CNBC. https://www.cnbc.com/2020/04/27/china-standards-2035-explained.html

Kitchin, R., \& Lauriault, T. P. (2014). Towards critical data studies: Charting and unpacking data assemblages and their work (Working Paper No. 2; The Programmable City). Maynooth University.

Koyt, A. (2020, July 2). The China Standards 2035 Plan: Is it a Follow-Up to Made in China 2025? China Briefing News. https://www.china-briefing.com/news/what-is-china-standards-2035-plan-ho w-will-it-impact-emerging-technologies-what-is-link-made-in-china-2025-goals/

Layne, C. (1997). From preponderance to offshore balancing. International Security, 22(1), 86. http s://doi.org/10.2307/2539331

Lee, K.-F. (2018). Al superpowers: China, Silicon Valley, and the new world order. Houghton Mifflin Harcourt.

Lenway, S., Morck, R., \& Yeung, B. (1996). Rent seeking, protectionism and innovation in the American steel industry. The Economic Journal, 106(435), 410-421. https://doi.org/10.2307/2235256

Lijian, Z. (2020a, August 10). Foreign Ministry Spokesperson Zhao Lijian's Regular Press Conference on August 10. Ministry of Foreign Affairs of the People's Republic of China. https://www.fmprc.gov.cn/m fa_eng/xwfw_665399/s2510_665401/2511_665403/t1805288.shtml 
Lijian, Z. (2020b, August 17). Foreign Ministry Spokesperson Zhao Lijian's Regular Press Conference on August 17. Ministry of Foreign Affairs of the People's Republic of China. https://www.fmprc.gov.cn/m fa_eng/xwfw_665399/s2510_665401/2511_665403/t1806940.shtml

Ljunggren, D. (2020, August 25). Canada has effectively moved to block China's Huawei from 5G, but can't say so. Reuters. https://www.reuters.com/article/us-canada-huawei-analysis-idUSKBN25L2 $6 \mathrm{~S}$

Lorenz, T., Browning, K., \& Frenkel, S. (2020). TikTok Teens Tank Trump Rally in Tulsa, They Say. The New York Times. https://www.nytimes.com/2020/06/21/style/tiktok-trump-rally-tulsa.html

Lynskey, O. (2017). Aligning data protection rights with competition law remedies? The GDPR right to data portability. European Law Review, 42(6), 793-814.

Maayan, P., \& Elkin-Koren, N. (2016). Accountability in Algorithmic Copyright Enforcement. Stanford Technology Law Review, 19, 473-533. https://law.stanford.edu/wp-content/uploads/2016/10/Accoun tability-in-Algorithmic-Copyright-Enforcement.pdf

Madiega, T. (2020). Digital sovereignty for Europe (Briefing PE 651.992; EPRS Ideas Papers). European Parliamentary Research Service.

Mann, M., \& Daly, A. (2020). Geopolitics, jurisdiction and surveillance. Internet Policy Review, 9(3). ht tps://policyreview.info/geopolitics-jurisdiction-surveillance

Mann, M., \& Warren, I. (2018). The digital and legal divide: Silk Road, transnational online policing and southern criminology. In K. Carrington, R. Hogg, J. Scott, \& M. Sozzo (Eds.), The Palgrave handbook of criminology and the global south (pp. 245-260). Palgrave MacMillan. https://doi.org/1 0.1007/978-3-319-65021-0_13

Mason, J., Sanders, C., \& Brunnstrom, D. (2020). Trump again raises idea of separating US economy from China. The Sydney Morning Herald. https://www.smh.com.au/business/the-economy/trump-agai n-raises-idea-of-separating-us-economy-from-china-20200908-p55tdb.html

Matamoros-Fernández, A. (2017). Platformed racism: The mediation and circulation of an Australian race-based controversy on Twitter, Facebook and YouTube. Information, Communication \& Society, 20(6), 930-946. https://doi.org/10.1080/1369118X.2017.1293130

Mayer, K. (2020, July 29). Fair competition and transparency benefits us all. TikTok Newsroom. http s://newsroom.tiktok.com/en-us/fair-competition-and-transparency-benefits-us-all

McCluskey, M. (2020, July 22). These TikTok Creators Say They're Still Being Suppressed for Posting Black Lives Matter Content. Time. https://time.com/5863350/tiktok-black-creators/

McGill, M. H. (2020). Under fire from Washington, TikTok pledges U.S. job growth. Axios. https://ww w.axios.com/tiktok-plans-to-add-10000-jobs-963c6ee4-9dbf-431f-9ac8-1bb381855df4.html

Microsoft. (2020, August 2). Microsoft to continue discussions on potential TikTok purchase in the United States [Blog post]. The Official Microsoft Blog. https://blogs.microsoft.com/blog/2020/08/02/ microsoft-to-continue-discussions-on-potential-tiktok-purchase-in-the-united-states/

Misty Hong v Bytedance Inc. Class Action Complaint, (US District Court Northern District of California 27 November 2019). https://www.courthousenews.com/wp-content/uploads/2019/12/Tik tok.pdf

Moshin, M. (2020, July 3). 10 TikTok Statistics That You Need to Know in 2021 [Blog post]. Oberlo. ht tps://au.oberlo.com/blog/tiktok-statistics 
O'Brien, R. (2020, June 24). The Chinese Communist Party's Ideology and Global Ambitions. The White House. https://trumpwhitehouse.archives.gov/briefings-statements/chinese-communist-partys-ideol ogy-global-ambitions/

O'Hara, K., \& Hall, W. (2018). Four internets: The geopolitics of digital governance (No. 206; CIGI Papers). https://www.cigionline.org/sites/default/files/documents/Paper\%20no.206web.pdf

O'loughlin, J. (1999). Ordering the 'crush zone': Geopolitical games in post-cold war eastern Europe. Geopolitics, 4(1), 34-56. https://doi.org/10.1080/14650049908407636

Pasquale, F. (2015). The black box society: The secret algorithms that control money and information. Harvard University Press.

Plantin, J.-C., Lagoze, C., Edwards, P. N., \& Sandvig, C. (2016). Infrastructure studies meet platform studies in the age of Google and Facebook. New Media \& Society, 20(1), 293-310. https://doi.org/1 $0.1177 / 1461444816661553$

Pohle, J., \& Thiel, T. (2020). Digital sovereignty. Internet Policy Review, 9(4). https://doi.org/10.1476 $3 / 2020.4 .1532$

Pompeo, M. (2020, August 5). Announcing the Expansion of the Clean Network to Safeguard America's Assets [Press statement]. U. S. Department of State. https://www.state.gov/announcing-the-expansi on-of-the-clean-network-to-safeguard-americas-assets/

Press Information Bureau Delhi. (2020, June 29). Government Bans 59 mobile apps which are prejudicial to sovereignty and integrity of India, defence of India, security of state and public order. Press Information Bureau, Government of India, Ministry of Electronics \& IT. pib.gov.in/Pressreleaseshar e.aspx?PRID=1635206

Roach, S. (2014). Unbalanced: The Codependency of America and China. Yale University Press.

Romm, T. (2020, July 30). Big tech hearing: Apple, Google, Facebook and Amazon CEOs testified before Congress. The Washington Post. https://www.washingtonpost.com/technology/2020/07/29/a pple-google-facebook-amazon-congress-hearing/

Sanger, D. E., \& Barnes, J. E. (2020, August 7). Is TikTok More of a Parenting Problem Than a Security Threat? The New York Times. https://www.nytimes.com/2020/08/07/us/politics/tiktok-secur ity-threat.html

Sharp, J. (2000). Refiguring Geopolitics (K. Dodds \& D. Atkinson, Eds.). Routledge.

Shead, S. (2020, May 27). TikTok owner ByteDance reportedly made a profit of $\$ 3$ billion on $\$ 17$ billion of revenue last year. CNBC. https://www.cnbc.com/2020/05/27/tiktok-bytedance-profit.html

Sicker, M. (2010). Geography and Politics Among Nations: An Introduction to Geopolitics. iUniverse.

Spangler, T. (2016, September 30). Musical.ly's Live.ly Is Now Bigger Than Twitter's Periscope on iOS (Study). Variety. https://variety.com/2016/digital/news/musically-lively-bigger-than-periscope-1201 875105/

Suzor, N. P. (2019). Lawless: The Secret Rules That Govern Our Digital Lives. Cambridge University Press. https://doi.org/10.1017/9781108666428

Suzor, N. P., Myers West, S., Quodling, A., \& York, J. (2019). What Do We Mean When We Talk About Transparency? Toward Meaningful Transparency in Commercial Content Moderation. International Journal of Communication, 13, 1526-1543. https://ijoc.org/index.php/ijoc/article/view/9736/0 
Svantesson, D. J. B. (2017). Solving the internet jurisdiction puzzle. Oxford University Press. https://do i.org/10.1093/oso/9780198795674.001.0001

Thussu, D. (2018). A new global communication order for a multipolar world. Communication Research and Practice, 4(1), 52-66. https://doi.org/10.1080/22041451.2018.1432988

TikTok. (2020). Tiktok Law Enforcement. https://www.tiktok.com/legal/law-enforcement

TikTok Newsroom. (2019, August 16). Statement on TikTok's content moderation and data security practices. TikTok Newsroom. https://newsroom.tiktok.com/en-us/statement-on-tiktoks-content-mod eration-and-data-security-practices

TikTok Newsroom. (2020a, June 19). How TikTok recommends videos \#ForYou. TikTok Newsroom. http s://newsroom.tiktok.com/en-us/how-tiktok-recommends-videos-for-you

TikTok Newsroom. (2020b, August 7). Statement on the Administration's Executive Order. TikTok Newsroom. https://newsroom.tiktok.com/en-us/tiktok-responds

Toal, G., Tuathail, G. Ó., Dalby, S., \& Routledge, P. (1998). The geopolitics reader. Routledge.

Trump, D. (2020a, July 31). Remarks by President Trump Before Marine One Departure. The White House. https://trumpwhitehouse.archives.gov/briefings-statements/remarks-president-trump-marin e-one-departure-073120/

Trump, D. (2020b, August 3). Remarks by President Trump in a Meeting with U.S. Tech Workers and Signing of an Executive Order on Hiring American. The White House. https://trumpwhitehouse.archive s.gov/briefings-statements/remarks-president-trump-meeting-u-s-tech-workers-signing-executiveorder-hiring-american/

Trump, D. (2020c, August 3). Remarks by President Trump in Press Briefing. https://trumpwhitehouse.a rchives.gov/briefings-statements/remarks-president-trump-press-briefing-august-3-2020/

Trump, D. (2020d, August 6). Executive Order on Addressing the Threat Posed by TikTok. The White House. https://trumpwhitehouse.archives.gov/presidential-actions/executive-order-addressing-thre at-posed-tiktok/

Trump, D. (2020e, August 6). Executive Order on Addressing the Threat Posed by WeChat. The White House. https://trumpwhitehouse.archives.gov/presidential-actions/executive-order-addressing-thre at-posed-wechat/

Trump, D. (2020f, August 14). Order Regarding the Acquisition of Musical.ly by ByteDance Ltd. The White House. https://trumpwhitehouse.archives.gov/presidential-actions/order-regarding-acquisitio n-musical-ly-bytedance-ltd/

Tusikov, N. (2019). How US-made rules shape internet governance in China. Internet Policy Review, 8(2). https://doi.org/10.14763/2019.2.1408

Utsunomiya, H., \& Takamiya, Y. (2020). Japan. In C. Jeffs (Ed.), E-Commerce Competition Enforcement Guide (3rd ed.). Global Competition Review. https://globalcompetitionreview.com/guide/e-commerc e-competition-enforcement-guide/third-edition/article/japan

van Dijck, J., Poell, T., \& Waal, M. (2018). The Platform Society (Vol. 1). Oxford University Press. http s://doi.org/10.1093/oso/9780190889760.001.0001

Wang, C. (2020, June 7). Why TikTok made its user so obsessive? The Al Algorithm that got you hooked [Blog post]. Towards Data Science. https://towardsdatascience.com/why-tiktok-made-its-use 
r-so-obsessive-the-ai-algorithm-that-got-you-hooked-7895bb1ab423

Wang, E. (2020, July 7). TikTok says it will exit Hong Kong market within days. Reuters. https://ww w.reuters.com/article/us-tiktok-hong-kong-exclusive-idUSKBN2480AD

Wells, G., Horwitz, J., \& Viswanatha, A. (2020, August 23). Facebook CEO Mark Zuckerberg Stoked Washington's Fears About TikTok. The Wall Street Journal. https://www.wsj.com/articles/facebook-ce o-mark-zuckerberg-stoked-washingtons-fears-about-tiktok-11598223133

Wenbin, W. (2020a, August 3). Foreign Ministry Spokesperson Wang Wenbin's Regular Press Conference on August 3. Ministry of Foreign Affairs of the People's Republic of China. https://www.fmprc.gov.cn/ mfa_eng/xwfw_665399/s2510_665401/2511_665403/t1803668.shtml

Wenbin, W. (2020b, August 4). Foreign Ministry Spokesperson Wang Wenbin's Regular Press Conference on August 4. Ministry of Foreign Affairs of the People's Republic of China. https://www.fmprc.gov.cn/ mfa_eng/xwfw_665399/s2510_665401/2511_665403/t1803971.shtml

Williams, K. (2020, February 7). Top Apps Worldwide for January 2020 by Downloads [Blog post]. Sensor Tower Blog. https://sensortower.com/blog/top-apps-worldwide-january-2020-by-downloads

Winseck, D. (2020). Vampire squids, 'the broken internet' and platform regulation. Journal of Digital Media \& Policy, 11(3), 241-282. https://doi.org/10.1386/jdmp_00025_1

Winseck, D., \& Puppis, M. (2020). Platform Regulation Inquiries [Unpublished manuscript].

Xiao, E., \& Lin, L. (2020, August 30). TikTok Talks Could Face Hurdle as China Tightens Tech Export Rules. The Wall Street Journal. https://www.wsj.com/articles/china-tightens-ai-export-restrictions-11 598703527

Xuetong, Y. (2019). The Age of Uneasy Peace: Chinese Power in a Divided World. Foreign Affairs, 98(1), 40-49. https://www.foreignaffairs.com/articles/china/2018-12-11/age-uneasy-peace

Yan, F. (2020, May 7). Diversity on Social Media: What We Can Learn From TikTok [Blog post]. RE-UP Agency. https://thisisreup.com/2020/05/07/diversity-on-social-media-what-we-can-learn-from-tikto k/

Zhang, Z. (2020). Infrastructuralization of TikTok: Transformation, power relationships, and platformization of video entertainment in China. Media, Culture \& Society, 43(2), 219-236. https://d oi.org/10.1177/0163443720939452 